\title{
Determination of the Minimum Inhibitory Concentrations of Alexidine and Chlorhexidine Against Enterococcus faecalis and Candida albicans: An In Vitro Study
}

Fatma Kermeoglu ${ }^{1}$, Umut Aksoy ${ }^{2}$, Atakan Kalender ${ }^{2}$, Meltem D. Oztan ${ }^{3}$, Ece I. Oguz ${ }^{4}$, Mehmet Kiyan ${ }^{5}$

1. Dentistry, Near East University 2. Endodontics, Near East University 3. Endodontics, Ankara university 4. Prosthodontics, Ankara university 5. Medical Microbiology, Ankara University School of Medicine, Ankara, TUR

$\square$ Corresponding author: Fatma Kermeoglu, dr.basmaci.f@gmail.com Disclosures can be found in Additional Information at the end of the article

\section{Abstract}

Introduction: The root canal system must be mechanically instrumented and chemically cleaned using various antimicrobial irrigants in a sequential manner or in combination for the elimination of necrotic pulp tissue and reducing the number of root canal bacteria. For this reason, new methods and materials are continuously being developed to achieve the objectives of endodontic treatment.

Materials and Methods: E. faecalis (ATCC 29212) and C. albicans (ATCC 90028) standard strains were used for this study. Colonies of E. faecalis and C. albicans were harvested from the agar plates and suspended in $4 \mathrm{~mL}$ of phosphate buffered saline (PBS). Microorganisms were diluted to obtain a suspension of approximately 108 colony-forming units $/ \mathrm{mL}$ (CFU/mL) in sterile PBS using McFarland standard tubes no. 0.5.

Results: After a two-minute contact time, all alexidine (ALX) concentrations used in this study eradicated all E. faecalis strains, while chlorhexidine (CHX) didn't kill 100\% of E. faecalis at $0.25 \%$ and lower concentrations even after a five-minute contact time. ALX also eradicated C. albicans at all concentrations even after a one-minute contact time. CHX showed antifungal activity against $\mathrm{C}$. albicans at all concentrations higher than $0.031 \%$ after a one-minute contact time.

Received 02/06/2018 Review began 02/09/2018 Review ended 02/19/2018 Published 02/23/2018

\section{(c) Copyright 2018}

Kermeoglu et al. This is an open access article distributed under the terms of the Creative Commons Attribution License CC-BY 3.0., which permits unrestricted use, distribution, and reproduction in any medium, provided the original author and source are credited.
Conclusion: A $0.0156 \%$ concentration of ALX can be a good alternative to CHX as an irrigation solution in endodontic treatment when used for one minute against E. faecalis and C. albicans.

\section{Categories: Other}

Keywords: alexidine, chlorhexidine, c. albicans, endodontic irrigants, e. faecalis

\section{Introduction}

Microorganisms and their by-products are regarded as the major cause of the formation and development of pulpal and periapical alterations [1-2]. Bacteria in the root canal organize either as free-floating single cells or organize communities attached to each other or to the 
areas of inaccessible root canal walls to form a biofilm [2-3]. Enterococcus faecalis (E. faecalis), a gram-positive facultative anaerobic microorganism capable of invading the dentinal tubules, is more likely to be found in persistent infections than in primary infections. Hence, many studies have been carried out on E. faecalis-infected dentin blocks to determine the antimicrobial activity of intracanal irrigants [4-6]. Another important consideration in endodontic treatment is the elimination of fungi from the root canal system. The largest proportion of the fungal oral microbiota is made up of the Candida species. Although studies demonstrated that fungi are not common members of the microbiota in primary endodontic infections, Candida albicans (C. albicans) has been associated with root canal infections resistant to nonsurgical therapy and potent pathogens to infect periapical lesions as E. faecalis $[7]$.

The primary objective of endodontic treatment is to clean, disinfect, and seal the root canal system from sources of infection [3]. Therefore, to eliminate necrotic pulp tissue and reduce the number of root canal bacteria, the root canal system must be mechanically instrumented and chemically cleaned using various antimicrobial irrigants in a sequential manner or in combination [8-9]. Although chemomechanical preparation does not result in the total elimination of bacteria from infected root canals, it is the most important step in endodontic disinfection. For this reason, new methods and materials are continuously being developed to achieve the objectives of endodontic treatment [10].

The use of irrigants helps provide residual antimicrobial activity, avoiding the negative impact that a bacteria invasion would have on the success of an endodontic procedure [11]. Sodium hypochlorite $(\mathrm{NaOCl})$ is the most frequently used root canal irrigation solution, which has a wide-ranging activity against endodontic microorganisms and dissolves necrotic tissues and debris through a complex biochemical process [3,7,12]. Despite the favorable qualities of $\mathrm{NaOCl}$, it has significant disadvantages, such as bad odor and taste, cytotoxicity, does not impart antimicrobial substantivity, and forms para-chloroaniline (PCA) after interaction with chlorhexidine (CHX) [13-15].

CHX is a cationic bisbiguanide disinfectant, which has also been widely used as an endodontic final irrigation solution, as it has antimicrobial action, proven substantivity, and inhibits the adherence of certain bacteria to dentin [16-18]. It has broad antimicrobial spectrum (i.e. against gram-positive/negative bacteria and fungi) at a concentration of $2 \%$ [19-20].

Alexidine (ALX), similar to CHX, is also a bisbiguanide, which has been used as an antiseptic in mouthwashes and as a disinfectant in contact lens solutions. It has an affinity for major virulence factors, such as bacterial lipopolysaccharide (LPS) and lipoteichoic acid (LTA) [6]. It differs chemically from CHX by the presence of two hydrophobic ethyl-hexyl end groups, as opposed to the p-chlorophenyl moieties of CHX [21-22]. Its structure provides hydrophobic penetration into membrane lipids and electrostatic adhesion to the negative sites of cell membranes [23-24]. In comparison with CHX, it has faster bactericidal activity and bacterial permeabilization $[22,25]$. Additionally, the interaction of ALX and $\mathrm{NaOCl}$ does not form an insoluble PCA precipitate [6].

The purpose of this study was to determine the minimum inhibitory concentration (MIC) values of CHX and ALX against E. faecalis and C. albicans for the effective use of ALX as a good alternative to $\mathrm{CHX}$ for root canal irrigation sequentially or in combination with $\mathrm{NaOCl}$.

\section{Materials And Methods}

\section{Microorganisms}

The E. faecalis (ATCC 29212) and C. albicans (ATCC 90028) standard strains were used for this 
study. For the regeneration of the lyophilized strains, $0.1 \mathrm{~mL}$ of the phosphate buffered saline (PBS) diluted E. faecalis (ATCC 29212) and C. albicans (ATCC 90028) were cultivated in $2 \mathrm{~mL}$ of brain-heart infusion broth (BHIB, HiMedia Lab., Pvt., Ltd. Mumbai, India). E. faecalis was subcultured on 5\% blood agar (Lab M, Lancashire, United Kingdom) and C. albicans was subcultured on Sabouraud dextrose agar (SDA, Lab M, Lancashire, United Kingdom) plates and incubated at $37^{\circ} \mathrm{C}$ for 24 hours. Microbial strains were confirmed by Gram's stain and by colonial and growth characteristics.

\section{Preparation of bacterial suspensions}

Colonies of E. faecalis and C. albicans were harvested from the agar plates and suspended in 4 $\mathrm{mL}$ of PBS. Microorganisms were diluted to obtain a suspension of approximately 108 colonyforming units $/ \mathrm{mL}(\mathrm{CFU} / \mathrm{mL})$ in sterile PBS using McFarland standard tubes no 0.5. The number of microorganisms per milliliter was determined by the optical densities of cultures at a wavelength of $600 \mathrm{nmol} \mathrm{L-1} \mathrm{(OD600)} \mathrm{by} \mathrm{spectrophotometer} \mathrm{(IMPLEN,} \mathrm{Munich,} \mathrm{Germany).}$

Microbial suspensions in PBS were vortexed for one minute. After 10-fold serial dilutions in PBS were prepared, $0.1 \mathrm{~mL}$ aliquots were plated onto blood agar plates at $37^{\circ} \mathrm{C}$ for 24 hours. Colonies were counted, and a log transformation was calculated.

\section{Root canal irrigants}

All CHX concentrations were prepared by diluting a 20\% solution of CHX (Sigma-Aldrich, St Louis, MO, USA) with sterile distilled water. An initial solution of $40 \mathrm{mg}$ ALX dihydrochloride powder (Santa Cruz Biotechnology, Inc, Dallas, Texas, USA) was dissolved in $10 \mathrm{ml}$ of $60 \%$ ethanol and 4\% ALX was prepared. Nine two-fold dilutions were made from this solution in sterile distilled water to obtain a concentration of $0.0039 \%$ ALX in a microtiter plate. The activity of ethanol on the biofilms at the concentrations used in the ALX solutions was formerly determined, showing that ethanol achieved a reduction of $\leqslant 0.5$ logarithmic units at all the concentrations tested, which is considered inconsequential. All the dilutions were carried out using sterile distilled water and were stored at room temperature until use, for no more than 60 minutes. The contact times of the irrigants on biofilms were one, two, three, and five minutes.

\section{Susceptibility testing of E. faecalis and C. albicans}

The susceptibility tests were done on a microtiter plate known as the "challenge plate." The dilutions of the irrigating solutions were placed along the length of the plate, allowing the first and last wells of each row to serve as the sterility and growth controls, respectively. The peg lid was submerged in the challenge plate (for one, two, three, and five minutes.). After exposure, $100 \mu \mathrm{E}$. faecalis or C. albicans suspensions were placed in a microtiter recovery plate, diluted serially in $0.9 \%$ saline and $50 \mu \mathrm{l}$ aliquots were plated on blood agar or SDA plates for viable cell counting. Ten replicates per irrigant concentration, period, and bacteria were performed. After a 24-hour incubation at $37^{\circ} \mathrm{C}$, subcultures were performed on blood agar or SDA plates from the wells, showing no visible growth in order to determine the bactericidal concentration of the irrigant.

The term "eradication" was used to denote the death of $100 \%$ of the bacterial population.

\section{Results}

The results of the antimicrobial activity of ALX and CHX against E. faecalis and C. albicans are shown in Table 1 and Table 2, respectively. ALX eradicated E. faecalis at all concentrations higher than $0.0078 \%$ after a one-minute contact time. CHX showed antimicrobial activity against E. faecalis at all concentrations higher than $0.5 \%$ after a one-minute contact time. After 


\section{Cureus}

a two-minute contact time, all ALX concentrations used in this study eradicated all E. faecalis strains, while CHX didn't kill $100 \%$ of E. faecalis at $0.25 \%$ and lower concentrations even after a five-minute contact time. ALX also eradicated C. albicans at all concentrations higher than $0.0156 \%$ only after a one-minute contact time. While CHX showed antifungal activity against C. albicans at all concentrations higher than $0.031 \%$ after the one-minute contact time, the 0.0039\% concentration of CHX did not eradicate C. albicans even after the five-minute contact time.

\begin{tabular}{|c|c|c|c|c|c|}
\hline & \multirow{3}{*}{$\begin{array}{l}\text { Concentrations } \\
\%\end{array}$} & \multicolumn{4}{|c|}{ E. faecalis (ATCC 29212) } \\
\hline & & \multicolumn{4}{|l|}{$\mathrm{CFU} / \mathrm{ml}( \pm \mathrm{SD})$} \\
\hline & & One min. & Two mins. & Three mins. & Five mins. \\
\hline \multirow{6}{*}{ Alexidine } & 0.125 & $\mathrm{E}$ & $\mathrm{E}$ & $\mathrm{E}$ & E \\
\hline & 0.0625 & $\mathrm{E}$ & E & E & E \\
\hline & 0.031 & $\mathrm{E}$ & E & $\mathrm{E}$ & $\mathrm{E}$ \\
\hline & 0.0156 & $\mathrm{E}$ & E & E & E \\
\hline & 0.0078 & $0.20 \times 10( \pm 0.08 \times 10)$ & E & $\mathrm{E}$ & E \\
\hline & 0.0039 & $\begin{array}{l}0.55 \times 10^{2} \\
\left( \pm 0.20 \times 10^{2}\right)\end{array}$ & E & $\mathrm{E}$ & E \\
\hline \multirow{8}{*}{ Chlorhexidine } & 4 & $E$ & E & $\mathrm{E}$ & E \\
\hline & 3 & $\mathrm{E}$ & $\mathrm{E}$ & $\mathrm{E}$ & $\mathrm{E}$ \\
\hline & 2 & $\mathrm{E}$ & $\mathrm{E}$ & E & E \\
\hline & 1 & $\mathrm{E}$ & E & $\mathrm{E}$ & $\mathrm{E}$ \\
\hline & 0.5 & $0.12 \times 10( \pm 0.12 \times 10)$ & E & E & E \\
\hline & 0.25 & $\begin{array}{l}2.55 \times 10^{3} \\
\left( \pm 2.56 \times 10^{3}\right)\end{array}$ & $\begin{array}{l}1.13 \times 10^{2} \\
\left( \pm 1.12 \times 10^{2}\right)\end{array}$ & $\begin{array}{l}0.22 \times 10 \\
( \pm 0.09 \times 10)\end{array}$ & $\begin{array}{l}0.02 \times 10 \\
( \pm 0.05 \times 10)\end{array}$ \\
\hline & 0.125 & $\begin{array}{l}1.01 \times 10^{4} \\
\left( \pm 0.57 \times 10^{4}\right)\end{array}$ & $\begin{array}{l}3.33 \times 10^{3} \\
\left( \pm 3.28 \times 10^{3}\right)\end{array}$ & $\begin{array}{l}3.35 \times 10 \\
( \pm 1.23 \times 10)\end{array}$ & $\begin{array}{l}0.42 \times 10 \\
( \pm 0.22 \times 10)\end{array}$ \\
\hline & \multicolumn{5}{|l|}{$\mathrm{E}$ : Erad } \\
\hline
\end{tabular}

\section{TABLE 1: Antimicrobial activity of ALX and CHX against E. faecalis}

Antimicrobial activity of $\mathrm{ALX}$ and $\mathrm{CHX}$ against $\mathrm{E}$. faecalis after different contact times: mean (SD)

ALX: alexidine; $\mathrm{CHX}$ : chlorhexidine 


\section{Cureus}

\begin{tabular}{|c|c|c|c|c|c|}
\hline & \multirow{3}{*}{$\begin{array}{l}\text { Concentrations } \\
\%\end{array}$} & \multicolumn{4}{|c|}{ C. albicans (ATCC 90128) } \\
\hline & & \multicolumn{4}{|l|}{ CFU/ml ( \pm SD) } \\
\hline & & One min. & Two mins. & Three mins. & Five mins. \\
\hline \multirow{6}{*}{ Alexidine } & 0.125 & $\mathrm{E}$ & $\mathrm{E}$ & $E$ & $E$ \\
\hline & 0.0625 & $\mathrm{E}$ & $\mathrm{E}$ & E & $\mathrm{E}$ \\
\hline & 0.031 & $\mathrm{E}$ & $\mathrm{E}$ & $\mathrm{E}$ & $\mathrm{E}$ \\
\hline & 0.0156 & $\mathrm{E}$ & E & E & $\mathrm{E}$ \\
\hline & 0.0078 & $\mathrm{E}$ & $\mathrm{E}$ & $E$ & $E$ \\
\hline & 0.0039 & $\mathrm{E}$ & $\mathrm{E}$ & E & $E$ \\
\hline \multirow{7}{*}{ Chlorhexidine } & 0.25 & $\mathrm{E}$ & $\mathrm{E}$ & $\mathrm{E}$ & $\mathrm{E}$ \\
\hline & 0.125 & $\mathrm{E}$ & $\mathrm{E}$ & $E$ & E \\
\hline & 0.0625 & $\mathrm{E}$ & $\mathrm{E}$ & $\mathrm{E}$ & $\mathrm{E}$ \\
\hline & 0.031 & $1.67 \times 10( \pm 1.88 \times 10)$ & $0.05 \times 10( \pm 0.1 \times 10)$ & $E$ & E \\
\hline & 0.0156 & $\begin{array}{l}4.25 \times 10^{2} \\
\left( \pm 2.32 \times 10^{2}\right)\end{array}$ & 2.30x10 ( $\pm 1.66 \times 10)$ & E & $\mathrm{E}$ \\
\hline & 0.0078 & $\begin{array}{l}4.62 \times 10^{3} \\
\left( \pm 2.49 \times 10^{3}\right)\end{array}$ & $\begin{array}{l}1.40 \times 10^{2} \\
\left( \pm 1.24 \times 10^{2}\right)\end{array}$ & $0.50 \times 10( \pm 0.46 \times 10)$ & E \\
\hline & 0.0039 & $\begin{array}{l}3.70 \times 10^{5} \\
\left( \pm 1.44 \times 10^{5}\right)\end{array}$ & $\begin{array}{l}7.47 \times 10^{3} \\
\left( \pm 1.14 \times 10^{3}\right)\end{array}$ & $\begin{array}{l}6.60 \times 10^{2} \\
\left( \pm 2.01 \times 10^{2}\right)\end{array}$ & $\begin{array}{l}0.25 \times 10 \\
( \pm 0.19 \times 10)\end{array}$ \\
\hline & E: Eradication & & & & \\
\hline
\end{tabular}

\section{TABLE 2: Antimicrobial activity of $A L X$ and $C H X$ against $C$. albicans}

Antimicrobial activity of $\mathrm{ALX}$ and $\mathrm{CHX}$ against $\mathrm{C}$. albicans after different contact times: mean (SD)

ALX: alexidine; $\mathrm{CHX}$ : chlorhexidine

\section{Discussion}

This study aims to evaluate the antimicrobial activity of two cationic molecules, ALX and CHX, against $\mathrm{E}$. faecalis and $\mathrm{C}$. albicans, which are the commonly isolated microorganisms from infected root canals.

The introduction of new antibacterial agents increases the need for antimicrobial sensitivity tests, which has received criticism, as all may show variability, particularly if insufficient attention is given to the careful standardization of technique. The tube dilution method appears to be one of the most reliable methods for determining the levels of microbial 
resistance to an antimicrobial agent [26]. The minimal/minimum inhibitory concentration (MIC) is the lowest concentration of an antimicrobial agent that inhibits the visible growth of bacteria. The lowest concentration preventing bacterial growth is considered the MIC [27].

We found that both ALX and CHX solutions were effective at low concentrations against E. faecalis and C. albicans. However, the MIC values for ALX were lower than CHX. In this study, after the two-minute contact time, all ALX dilutions eradicated E. faecalis, whereas only $0.5 \%$ and higher concentrations of $\mathrm{CHX}$ eradicated $\mathrm{E}$. faecalis. The results of the present study are in accordance with the findings of Barrios et al. who showed that $2 \%$ and $1 \%$ ALX used for one minute provide longer antimicrobial substantivity against $\mathrm{E}$. faecalis than $\mathrm{CHX}$ when applied to $2 \%$ and $0.5 \%$ [25]. However, Kim et al. found that $1 \%$ ALX was effective against E. faecalis infection and there was no difference in antibacterial activity against E. faecalis between $1 \%$ ALX and 2\% CHX [6].

In the present study, ALX showed antifungal activity against C. albicans at all concentrations only after a one-minute contact time, whereas only $0.031 \%$ and higher concentrations of $\mathrm{CHX}$ showed antifungal activity after a one-minute contact time. Our results also indicated that the antifungal efficacy of ALX was significantly better than CHX against C. albicans. These findings are in agreement with Roberts \& Addy, who compared the bactericidal properties of $0.2 \%$ CHX gluconate mouthwash and $0.035 \%$ ALX mouthwash [27]. They concluded that both antiseptics were similar in action, being effective against $\mathrm{C}$. albicans at low concentrations. The results of the present study are also in line with the findings of Yanai et al. regarding the antifungal efficacy of ALX [28]. They found that ALX manifests robust and rapid antimicrobial activity against bacteria and fungi under ideal conditions. However, the antifungal activity of ALX decreased as the $\mathrm{NaCl}$ concentration increased, whereas antibacterial activity remained unaffected. These findings indicated that electrostatic and hydrophobic balance in ALX is important for antimicrobial activity.

These results evidence that ALX effectiveness is both time- and concentration-dependent, as is CHX [29]. However, ALX kills E. faecalis even at a 100-fold lower concentration than CHX. Also, Silveira et al., whose study aimed to evaluate the antimicrobial activity of ALX alone and combined with $\mathrm{N}$-acetylcysteine (NAC) against two E. faecalis strain biofilms found that ALX showed antimicrobial properties tested at very low concentrations [29]. This outcome might be the result of ALX having a greater affinity for bacterial lipoteichoic acid (LTA), which is a major constituent of the cell wall of gram-positive bacteria, than CHX.

Because of its tissue-dissolving capability as well as its broad antimicrobial action and ability to neutralize toxic products, $\mathrm{NaOCl}$ is the most commonly used irrigation solution in endodontic treatment [30]. Although color change and the formation of a dense-brown precipitate, containing PCA, after the reaction of $\mathrm{NaOCl}$ and $\mathrm{CHX}$ have been reported, Kim et al. reported that the association of ALX/NaOCl did not produce PCA or any precipitate [30]. ALX can be used as an effective canal irrigant sequentially or in combination with $\mathrm{NaOCl}$.

\section{Conclusions}

The results of this study presented that $0.0156 \%$ ALX can be a good alternative to CHX as an irrigation solution in endodontic treatment when used for one minute against $\mathrm{E}$. faecalis and $C$. albicans. Laboratory tests are only the first steps in a study of the antimicrobial effects of antiseptics. The bacterial efficiency of irrigation solutions in tube dilution studies may not demonstrate clinical conditions. This study should be followed by a clinical study for a final evaluation of the antimicrobial capability of ALX as a root canal irrigant.

\section{Additional Information}




\section{Disclosures}

Human subjects: All authors have confirmed that this study did not involve human participants or tissue. Animal subjects: All authors have confirmed that this study did not involve animal subjects or tissue. Conflicts of interest: In compliance with the ICMJE uniform disclosure form, all authors declare the following: Payment/services info: All authors have declared that no financial support was received from any organization for the submitted work. Financial relationships: All authors have declared that they have no financial relationships at present or within the previous three years with any organizations that might have an interest in the submitted work. Other relationships: All authors have declared that there are no other relationships or activities that could appear to have influenced the submitted work.

\section{References}

1. Kakehashi S, Stanley HR, Fitzgerald RJ: The effects of surgical exposures of dental pulps in germ-free and conventional laboratory rats. Oral Surg Oral Med Oral Pathol. 1965, 20:340349. 10.1016/0030-4220(65)90166-0

2. Möller AJ, Fabricius L, Dahlen G, Ohman AE, Heyden G: Influence on periapical tissues of indigenous oral bacteria and necrotic pulp tissue in monkeys. Scand J Dent Res. 1981, 89:475484.

3. Abbaszadegan A, Khayat A, Motamedifar M: Comparison of antimicrobial efficacy of IKI and $\mathrm{NaOCl}$ irrigants in infected root canals: an in vivo study. Iran Endod J. 2010, 5:101-106.

4. Giardino L, Ambu E, Savoldi E, Rimondini R, Cassanelli C, Debbia EA: Comparative evaluation of antimicrobial efficacy of sodium hypochlorite, MTAD, and tetraclean against Enterococcus faecalis biofilm. J Endod. 2007, 33:852-855. 10.1016/j.joen.2007.02.012

5. Arias-Moliz MT, Ferrer-Luque CM, Espigares-Garcia M, Baca P: Enterococcus faecalis biofilms eradication by root canal irrigants. J Endod. 2009, 35:711-714. 10.1016/j.joen.2009.01.018

6. Kim HS, Woo Chang S, Baek SH, Han SH, Lee Y, Zhu Q, Kum KY: Antimicrobial effect of alexidine and chlorhexidine against Enterococcus faecalis infection. Int J Oral Sci. 2013, 5:2631. 10.1038/ijos.2013.11

7. Mohammadi Z, Giardino L, Palazzi F: Evaluation of the antifungal activity of four solutions used as a final rinse in vitro. Aust Endod J. 2013, 39:31-34. 10.1111/j.1747-4477.2010.00278.x

8. Waltimo T, Trope M, Haapasalo M, Orstavik D: Clinical efficacy of treatment procedures in endodontic infection control and one year follow-up of periapical healing. J Endod. 2005, 31:863-866. 10.1097/01.don.0000164856.27920.85

9. Zehnder M: Root canal irrigants. J Endod. 2006, 32:389-398. 10.1016/j.joen.2005.09.014

10. Pappen FG, Shen Y, Qian W, Giardino L, Haapasalo M: In vitro antibacterial action of tetraclean, MTAD and five experimental irrigation solutions. Int Endod J. 2010, 43:528-535.

11. Mohammadi Z, Abbott PV: Antimicrobial substantivity of root canal irrigants and medicaments: a review. Aust Endod J. 2009, 35:131-139.

12. Byström A, Sundqvist G: The antibacterial action of sodium hypochlorite and EDTA in 60 cases of endodontic therapy. Int Endod J. 1985, 18:35-40.

13. Mountouris G, Silikas N, Eliades G: Effect of sodium hypochlorite treatment on the molecular composition and morphology of human coronal dentin. J Adhes Dent. 2004, 6:175-182. 10.3290/j.jad.a9506

14. Barnhart BD, Chuang A, Lucca JJ, Roberts S, Liewehr F, Joyce AP: An in vitro evaluation of the cytotoxicity of various endodontic irrigants on human gingival fibroblasts. J Endod. 2005, 31:613-615. 10.1097/01.don.0000153840.94227.87

15. Marending M, Luder HU, Brunner TJ, Knecht S, Stark WJ, Zehnder M: Effect of sodium hypochlorite on human root dentine-mechanical, chemical and structural evaluation. Int Endod J. 2007, 40:786-793.

16. Mohammadi Z, Abbott PV: The properties and applications of chlorhexidine in endodontics . Int Endod J. 2009, 42:288-302. 10.1111/j.1365-2591.2008.01540.x

17. Carrilho MR, Carvalho RM, Sousa EN, et al.: Substantivity of chlorhexidine to human dentin. Dent Mater. 2010, 26:779-785. 10.1016/j.dental.2010.04.002

18. Baca P, Junco P, Arias-Moliz MT, Castillo F, Rodríguez-Archilla A, Ferrer-Luque CM: Antimicrobial substantivity over time of chlorhexidine and cetrimide . J Endod. 2012, 38:927- 
930. 10.1016/j.joen.2012.04.003

19. Zamany A, Safavi K, Spangberg LS: The effect of chlorhexidine as an endodontic disinfectant . Oral Surg Oral Med Oral Pathol Oral Radiol and Endod. 2003, 96:578-581. 10.1016/S10792104(03)00168-9

20. Gilbert P, Moore LE: Cationic antiseptics: diversity of action under a common epithet . J Appl Microbiol. 2005, 99:703-715.

21. McDonnell G, Russell AD: Antiseptics and disinfectants: activity, action, and resistance. Clin Microbiol Rev. 1999, 12:147-179.

22. Zorko M, Jerala R: Alexidine and chlorhexidine bind to lipopolysaccharide and lipoteichoic acid and prevent cell activation by antibiotics. J Antimicrob Chemother. 2008, 62:730-737. 10.1093/jac/dkn270

23. Chawner JA, Gilbert P: Interaction of the bisbiguanides chlorhexidine and alexidine with phospholipid vesicles: evidence for separate modes of action. J Appl Bacteriol. 1989, 66:253258. 10.1111/j.1365-2672.1989.tb02476.x

24. Chawner JA, Gilbert P: A comparative study of the bactericidal and growth inhibitory activities of the bisbiguanides alexidine and chlorhexidine. J Appl Bacteriol. 1989, 66:243-252. 10.1111/j.1365-2672.1989.tb02475.x

25. Barrios R, Ferrer-Luque CM, Arias-Moliz MT, Ruiz-Linares M, Bravo M, Baca P: Antimicrobial substantivity of alexidine and chlorhexidine in dentin. J Endod. 2013, 39:1413-1415. 10.1016/j.joen.2013.07.038

26. Jorgensen JH, Ferraro MJ: Antimicrobial susceptibility testing: a review of general principles and contemporary practices. Clin Infect Dis. 2009, 49:1749-1755. 10.1086/647952

27. Roberts WR, Addy M: Comparison of the in vivo and in vitro antibacterial properties of antiseptic mouthrinses containing chlorhexidine, alexidine, cetyl pyridinium chloride and hexetidine. Relevance to mode of action. J Clin Periodontol. 1981, 8:295-310.

28. Yanai R, Ueda K, Nishida T, Toyohara M, Mori O: Effects of tonicity-adjusting and surfactant agents on the antimicrobial activity of alexidine. Eye Contact Lens. 2011, 37:57-60. 10.1097/ICL.0b013e31820ca361

29. Silveira LFM, Baca P, Arias-Moliz MT, Rodriguez-Archilla A, Ferrer-Luque CM: Antimicrobial activity of alexidine alone and associated with $\mathrm{N}$-acetylcysteine against Enterococcus faecalis biofilm. Int J Oral Sci. 2013, 5:146-149. 10.1038/ijos.2013.58

30. Kim HS, Zhu Q, Baek SH, et al.: Chemical interaction of alexidine and sodium hypochlorite. J Endod. 2012, 38:112-116. 10.1016/j.joen.2011.10.003 